\title{
Effect of microalgae incorporation on the physicochemical, nutritional, and sensorial properties of an innovative broccoli soup
}

\author{
Tomás Lafarga ${ }^{\mathrm{a}, *}$, Francisco Gabriel Acién-Fernández ${ }^{\mathrm{b}}$, Massimo Castellari ${ }^{\mathrm{c}}$, Silvia Villaróa ${ }^{\mathrm{a}}$, \\ Gloria Bobo $^{\mathrm{a}}$, Ingrid Aguiló-Aguayo ${ }^{\mathrm{a}}$ \\ ${ }^{a}$ Institute of Agriculture and Food Research and Technology, Postharvest, Parc Científic I Tecnològic Agroalimentari de Lleida, 25003, Lleida, Spain \\ ${ }^{\mathrm{b}}$ University of Almería, Department of Chemical Engineering, Almería, Spain \\ ${ }^{\mathrm{c}}$ Institute of Agriculture and Food Research and Technology, Food Industries, Finca Camps I Armet, Monells, Spain
}

\section{A R T I C L E I N F O}

\section{Keywords:}

Functional foods

Spirulina sp.

Chlorella sp.

Tetraselmis sp.

Novel ingredients

\begin{abstract}
A B S T R A C T
The aim of this paper was to develop broccoli soups enriched in Spirulina sp., Chlorella sp., or Tetraselmis sp., at concentrations ranging from 0.5 to $2.0 \%(\mathrm{w} / \mathrm{v})$, and to assess the effect of microalgae incorporation on their quality and acceptance. Incorporation of freeze-dried microalgae biomass into the broccoli soup resulted in lower $L^{*}$ values, especially after incorporation of Spirulina sp. and Chlorella sp. Microalgae incorporation also led to an increased content of polyphenols and to a higher antioxidant capacity. Microalgae-containing soups showed a higher amount of bioaccessible polyphenols, calculated after a simulated gastrointestinal digestion (ranging between $32.9 \pm 1.1$ and $45.6 \pm 0.5 \mathrm{mg} / 100 \mathrm{~mL}$ ). The acceptability index of soups formulated using lower microalgae concentrations was over $70 \%$ suggesting that the soups would be well accepted. Indeed, the purchase intention of the soups containing microalgae at $0.5 \%(\mathrm{w} / \mathrm{v})$ ranged between 3.4 and 4.1 (assessed using a 5-point hedonic scale).
\end{abstract}

\section{Introduction}

Microalgae biotechnology has increased exponentially over the last decade (Garrido-Cardenas, Manzano-Agugliaro, Acien-Fernandez, \& Molina-Grima, 2018). This promising natural resource is being used (or studied) as animal or aquatic feed, in wastewater treatment or bioremediation applications, as a bio-fertiliser, and as a raw material for the generation of biofuels and high-value products such as pigments or bioactive compounds, among other applications (Rizwan, Mujtaba, Memon, Lee, \& Rashid, 2018). Microalgae are, however, mainly used for human consumption as they contain a large number of valuable compounds that can supplement the nutritional energy needs of the currently expanding population (Vaz, Moreira, Morais, \& Costa, 2016). However, despite the high content of macro- and micro-nutrients found in microalgae, only a limited number of products containing microalgae have been launched into the market.

Several scientific publications, recently reviewed by Caporgno and Mathys (2018), evaluated the potential of microalgae and microalgaederived compounds for being used as novel ingredients with either functional or technofunctional properties into dairy products, pasta, or baked goods such as cookies or bread. The majority of these studies attempted (and achieved) to improve the nutritional properties of foods by incorporating microalgae biomass into their recipes (Gouveia et al., 2008; Rodríguez De Marco, Steffolani, Martínez, \& León, 2014). However, only a limited number of studies evaluated the flavour and the acceptance of these products after a sensorial analysis. In most of the studies where a sensorial analysis was carried out, the authors reported relatively high acceptability scores and that higher microalgae concentrations resulted in reduced overall acceptance (Caporgno \& Mathys, 2018). One reason could be that dairy products and baked goods are not naturally green, and the green colour of microalgae can adversely affect consumers' perception about taste and quality (Becker, 2007). The acceptance of foods is also determined by health concerns and consumers' familiarity with the food ingredients, among other issues (Sandmann et al., 2015). Up the best of our knowledge, there are no studies evaluating the effect of microalgae incorporation into vegetable soups. Moreover, most of the studies carried out to date assessed the effect of incorporating Spirulina or Chlorella into foods. This makes sense, as these two strains are accepted for human consumption and are currently the most cultivated strains (Garrido-Cardenas et al., 2018). However, there are thousands of microalgae strains available in culture collections worldwide and some of these have finally achieved commercial-scale success. For example, Fitoplancton Marino S.L. (Cadiz, Spain) recently launched the product Plancton Marino Veta la Palma,

\footnotetext{
* Corresponding author.

E-mail address: tomas.lafarga@irta.cat (T. Lafarga).
} 
which is a freeze-dried Tetraselmis chuii product that has been authorized by the European Food Safety Authority (EFSA) to be marketed as a novel food in accordance with Article 3(1) of Regulation (EC) No 258/ 97 (AESAN, 2014).

The consumption of these underutilised strains would not only open novel commercial opportunities to processors but also potentially promote health. Therefore, the aim of the current manuscript was to develop a novel food product enriched with Spirulina sp., Chlorella sp., and Tetraselmis sp. biomass, all of them authorised for human consumption in the EU (Acién Fernández, Fernández Sevilla, \& Molina Grima, 2018). The food matrix in which the microalgae biomass was incorporated was broccoli soup, which is naturally green and generally associated with positive health outcomes. The current paper also aimed at evaluating the effect of microalgae incorporation on the overall quality and acceptance of the end product. Parameters evaluated included colour, texture, antioxidant activity, total phenolic content (TPC), and a visual and sensorial analysis that involved assessment of flavour, texture, overall acceptance, and purchase intention.

\section{Materials and methods}

\subsection{Preparation of the microalgae-containing broccoli soup}

Soups were made according to the formulations listed in Table 1 at the pilot plant facilities of IRTA Fruitcentre (Lleida, Spain). Briefly, broccoli florets were cut off from their stalks and boiled at a broccoli:boiling water ratio of 1:1.5 (w/v) for $7 \mathrm{~min}$. Once cooked, the broccolis were sieved and the boiling water was collected. Boiled broccolis, the recovered boiling water, and olive oil, at the concentrations listed in Table 1, were pulled together and homogenized using a TF410/450W industrial blender (Irimar, Valencia, Spain) operating at maximum speed for $4 \mathrm{~min}$. Then, the salt and the microalgal biomass were incorporated, resuspended in water at a concentration calculated to keep the water content of the different soups constant. All the ingredients were further homogenised for $1 \mathrm{~min}$ and boiled for a further $2 \mathrm{~min}$ period. Microalgae concentrations were selected based on preliminary experiments carried out to establish the maximum microalgae inclusion level that did not negatively affect the organoleptic properties of the soups - Higher microalgae concentrations resulted in unacceptable overall acceptability scores (data not shown). Soups were immediately chilled to $4^{\circ} \mathrm{C}$ using an ABT 101L blast chiller (Infrico, Barcelona, Spain). Each soup was divided into two lots. The first one was used for visual, sensorial, and physicochemical analyses and was stored at $4{ }^{\circ} \mathrm{C}$ until further analysis (approximately $24 \mathrm{~h}$ ). The second lot was used for determination of antioxidant capacity and total phenolic content (TPC) and was stored at $-20^{\circ} \mathrm{C}$.

\subsection{Viscosity and water- and oil-holding capacities}

WHC and OHC were determined following the methodology described by Lafarga, Álvarez, Bobo, and Aguiló-Aguayo (2018) and using a Sigma 3-18 KS centrifuge (Sigma Laborzentrifugen $\mathrm{GmbH}$, Osterode am Harz, Germany). Determinations were carried out in triplicate for each microalgae specie and results were expressed either as $g$ of water or sunflower oil per $g$ or freeze-dried microalgae. Viscosity was measured using a ST-2020 L rotary viscometer (JP Selecta, Barcelona, Spain) at $40 \pm 1{ }^{\circ} \mathrm{C}$ and in duplicate. Results were expressed as Pa.s.

\subsection{Colour}

Colour recordings of the soups were taken in triplicate using a Minolta CR-200 colorimeter (Minolta INC, Tokyo, Japan) as described by Lafarga et al. (2018). Chroma (Ch) and difference from the control $(\delta E)$ values were calculated using the following equations:

$C h=\sqrt{a^{* 2}+b^{* 2}}$

$\delta E=\sqrt{\left(L_{C K}^{*}-L_{i}^{*}\right)^{2}+\left(a_{C K}^{*}-a_{i}^{*}\right)^{2}+\left(b_{C K}^{*}-b_{i}^{*}\right)^{2}}$

where $\boldsymbol{L}_{\boldsymbol{C K}}^{*}, \boldsymbol{a}_{C K}^{*}$, and $\boldsymbol{b}_{C K}^{*}$ are the colour parameters of the control soup and $\boldsymbol{L}_{\boldsymbol{i}}^{*}, \boldsymbol{a}_{\boldsymbol{i}}^{*}$, and $\boldsymbol{b}_{\boldsymbol{i}}^{*}$ the colour parameters of each broccoli-containing soup.

\subsection{Determination of total phenolic content}

The TPC was determined by the Folin-Ciocalteu method as described by Lafarga, Ruiz-Aguirre, et al. (2019) and Lafarga, Villaró, et al. (2019). Briefly, for the extraction of polyphenols, the soups were homogenised with methanol $70 \%(\mathrm{v} / \mathrm{v})$ at a sample:methanol ratio of $1: 4(\mathrm{w} / \mathrm{v})$ at room temperature. Samples were homogenised using a T25 ULTRA-TURRAX $^{\oplus}$ homogeniser (IKA, Staufen, Germany) operating at $14,000 \mathrm{rpm}$ for $30 \mathrm{~s}$. Immediately after homogenisation, samples were placed on a stirrer at room temperature for $2 \mathrm{~h}$ and centrifuged using a Sigma-3-18 KS centrifuge (Sigma Laborzentrifugen $\mathrm{GmbH}$, Osterode am Harz, Germany) operating at $12,000 \mathrm{rpm}$ for $20 \mathrm{~min}$. TPC was determined in triplicate using a GENESYS ${ }^{\mathrm{TM}} 10 \mathrm{~S}$-UV Vis spectrophotometer (Thermo Fisher Scientific, MA, USA). Results were expressed as mg of gallic acid equivalents per $100 \mathrm{~mL}$ of soup. Standard curves were prepared daily.

\subsection{Assessment of antioxidant activity}

Antioxidant activity was determined using both the ferric ion reducing antioxidant power (FRAP) and the DPPH scavenging activity assays as described by Lafarga, Ruiz-Aguirre, et al. (2019) and Lafarga,

Table 1

Composition of the broccoli soups containing microalgae.

\begin{tabular}{|c|c|c|c|c|c|}
\hline & Boiled broccoli (g) & Broccoli boiling water $(\mathrm{g})^{\mathrm{a}}$ & Olive oil (g) & Salt $(g)^{b}$ & Freeze-dried microalgae (g) \\
\hline CK: Control & 47,8 & 44,7 & 7 & 0,50 & 0,0 \\
\hline S1: Spirulina sp. $0.5 \%(\mathrm{w} / \mathrm{w})$ & 47,2 & 44,8 & 7 & 0,50 & 0,5 \\
\hline S2: Spirulina sp. $1.0 \%(\mathrm{w} / \mathrm{w})$ & 46,6 & 44,9 & 7 & 0,50 & 1,0 \\
\hline S3: Spirulina sp. $1.5 \%(\mathrm{w} / \mathrm{w})$ & 46,0 & 45,0 & 7 & 0,50 & 1,5 \\
\hline S4: Spirulina sp. $2.0 \%(\mathrm{w} / \mathrm{w})$ & 45,4 & 45,1 & 7 & 0,50 & 2,0 \\
\hline C1: Chlorella sp. $0.5 \%(\mathrm{w} / \mathrm{w})$ & 47,2 & 44,8 & 7 & 0,50 & 0,5 \\
\hline C2: Chlorella sp. $1.0 \%(\mathrm{w} / \mathrm{w})$ & 46,6 & 44,9 & 7 & 0,50 & 1,0 \\
\hline C3: Chlorella sp. $1.5 \%(\mathrm{w} / \mathrm{w})$ & 46,0 & 45,0 & 7 & 0,50 & 1,5 \\
\hline C4: Chlorella sp. $2.0 \%(\mathrm{w} / \mathrm{w})$ & 45,4 & 45,1 & 7 & 0,50 & 2,0 \\
\hline $\mathrm{T} 1:$ Tetraselmis sp. $0.5 \%(\mathrm{w} / \mathrm{w})$ & 47,2 & 44,8 & 7 & 0,38 & 0,5 \\
\hline T2: Tetraselmis sp. $1.0 \%(\mathrm{w} / \mathrm{w})$ & 46,6 & 44,9 & 7 & 0,35 & 1,0 \\
\hline T3: Tetraselmis sp. $1.5 \%(\mathrm{w} / \mathrm{w})$ & 46,0 & 45,0 & 7 & 0,33 & 1,5 \\
\hline T4: Tetraselmis sp. $2.0 \%(\mathrm{w} / \mathrm{w})$ & 45,4 & 45,1 & 7 & 0,30 & 2,0 \\
\hline
\end{tabular}

a The amount of water used in different formulations varied to achieve a comparable water content in each formulation: $87.7 \pm 0.8 \%$.

b Salt content of soups formulated using Tetraselmis sp. had to be re-adjusted because of the salty taste of the microalgal biomass. 
Villaró, et al. (2019). Antioxidant activity was determined in triplicate using the same extracts used for determination of TPC and results were expressed as mg of ascorbic acid equivalents per $100 \mathrm{~mL}$. Standard curves were prepared daily.

\subsection{Simulated gastrointestinal digestion}

A simulated gastrointestinal digestion of the control and microalgae-containing soups was done following the method of Minekus et al. (2014). A blank was prepared using only distilled water instead of the sample and following the same procedure. Determinations of TPC and antioxidant activity were performed after the intestinal phase as described in previous sections.

\subsection{Sensorial and visual analysis}

Both visual and sensorial analysis were undertaken approximately $24 \mathrm{~h}$ after the soups were made with 30 semi-trained consumers (17 women, 13 men, age 20-50 years) recruited from IRTA Fruitcentre (Lleida, Spain) who would be willing to buy the product. Consumers were considered as semi-trained as all of them were familiar with the quality attributes of vegetable soups and were capable of discriminating differences and communicating their reactions, though they were not formally trained. Sensory evaluation was conducted in a sensory laboratory with separate booths. Briefly, approximately $30 \mathrm{~mL}$ of the soups were place in white polystyrene glasses labelled with random codes and presented to the panellists in a randomised order. Each panellists assessed a maximum of five samples per day and all the panellists assessed all of the samples. A 60-s time laps was employed between each sensory palate to reduce sensory fatigue. Panellists assessed the samples and were asked to indicate his or her opinion on the flavour and the overall acceptance of the soups using a nine-point hedonic scale (from 1: dislike extremely to 9: like extremely) as described by Amaral et al., 2018 and Souza et al., 2019. The acceptability index was calculated using the following equation:

Acceptability index $(\%)=\frac{X}{9} 100$

where $X$ is the mean of the scores obtained for overall acceptance.

To assess flavour and texture, soups were given to the panellists with the green lights of the sensory booths on to mask the soups colour. Purchase intention was assessed using a five-point hedonic scale which ranged from 1: certainly would not buy to 5: certainly would buy (Lucas, Morais, Santos, \& Costa, 2018). Finally, for assessment of visual appearance, $300 \mathrm{~mL}$ of the soups were put into $300 \mathrm{~mL}$ glass bottles (commercially used for storing soups and sauces), simulating the final presentation of the product. Each panellist assessed all the samples and was asked to indicate his or her opinion on the overall visual appearance of the soups, focusing on their colour and texture and using a ninepoint hedonic scale (from 1: dislike extremely to 9: like extremely).

\subsection{Statistical analysis}

Results are expressed as mean \pm standard deviation (S.D.). Differences between samples were analysed using analysis of variance (ANOVA) with JMP 13 (SAS Institute Inc., Cary, USA). Where significant differences were present, a Tukey pairwise comparison of the means was conducted to identify where the sample differences occurred. The criterion for statistical significance was $p<0.05$. To identify relationships between parameters, bivariate Pearson's correlation analysis was carried out.

\section{Results and discussion}

\subsection{Functional and antioxidant properties of the microalgal biomass}

Colour attributes of the dried microalgal biomass were measured. The $L^{*}$ value was $32.58 \pm 0.61,35.06 \pm 0.21$, and $40.16 \pm 0.12$ for Spirulina sp., Chlorella sp., and Tetraselmis sp., respectively. In addition, $a^{*}$ values were measured as $-1.66 \pm 0.15,-3.38 \pm 0.40$, and $-7.81 \pm 0.12$ for Spirulina sp., Chlorella sp., and Tetraselmis sp., respectively. Overall, Tetraselmis showed the highest $L^{*}$ and the lowest $a^{*}$ values $(p<0.05)$, suggesting a lighter and greener hue when compared to powdered Spirulina sp. and Chlorella sp.

The WHC of the dried microalgal biomass was $1.96 \pm 0.05$, $1.48 \pm 0.07$, and $0.99 \pm 0.20 \mathrm{~g} / \mathrm{g}$ for Spirulina sp., Chlorella sp., and Tetraselmis sp., respectively. Tetraselmis sp. showed the lowest WHC values $(p<0.05)$, probably caused by the higher salt content of the biomass which was dissolved in water during the assay. In addition, the OHC of Spirulina sp., Chlorella sp., and Tetraselmis sp. was $1.64 \pm 0.10$, $1.47 \pm 0.23$, and $1.23 \pm 0.15$, respectively. Similar WHC and OHC values were previously reported for proteins extracted from pulses (Lafarga, Álvarez, et al., 2018) or microalgae (Waghmare, Salve, LeBlanc, \& Arya, 2016). Interactions of food ingredients with water and oil are of key importance in the food industry because these will affect flavour and texture of foods (Kumar, Ganesan, Selvaraj, \& Rao, 2014). High WHC values are desirable in viscous foods such as vegetable soups, sauces, or custards to provide thickening and viscosity. Microalgal cells are grown in suspension, and are therefore not water soluble. Because of this, and based on their WHC and OHC values, microalgae can be used to provide not only colour and flavour to foods but also thickening and viscosity.

The antioxidant capacity of the powdered microalgae was also determined. When assessed using the FRAP assay, the antioxidant capacity of Spirulina sp., Chlorella sp., and Tetraselmis sp. was $356.23 \pm 16.88,224.11 \pm 9.65$, and $308.67 \pm 22.58 \mathrm{mg} / 100 \mathrm{~g}$ of dry weight, respectively. Moreover, when assessed using the DPPH assay, the antioxidant capacity of selected microalgae was $304.66 \pm 9.54,195.23 \pm 3.97$, and $254.33 \pm 11.97 \mathrm{mg} / 100 \mathrm{~g}$ of dry weight, respectively. Similar antioxidant capacity values were reported previously (Goiris et al., 2012; Li et al., 2007).

\subsection{Physicochemical attributes}

Colour attributes of the soups were significantly affected by microalgae concentration $(p<0.001)$, specie $(p<0.001)$, and the interaction of both factors $(p<0.001)$. Incorporation of freeze-dried microalgae biomass into the broccoli soup resulted in lower $L^{*}$ values, which means that microalgae-containing soups presented a darker colour (Fig. 1). As expected, higher microalgae concentration resulted in lower $L^{*}$ values. A negative correlation was observed between $L^{*}$ values and the concentration of Spirulina sp. $\left(r^{2}=0.9600 ; p<0.001\right)$, Chlorella sp. $\left(r^{2}=0.7847 ; p<0.05\right)$, and Tetraselmis sp. $\left(r^{2}=0.9872\right.$; $p<0.001$ ). The $a^{*}$ parameter was for all the studied samples negative, which denotes a greenish colour. Tetraselmis sp. incorporation into the broccoli soup resulted in lower $a^{*}$ values when compared to the control and to soups formulated using Chlorella sp. or Spirulina sp. $(p<0.05)$. This is clear in Fig. 1, where T1-T4 show a more distinctive green colour. Indeed, positive correlations were observed between $a^{*}$ values and Spirulina sp. $\left(r^{2}=0.9875 ; p<0.001\right)$, Chlorella sp. $\left(r^{2}=0.8244\right.$; $p<0.001)$, and Tetraselmis sp. $\left(r^{2}=0.9399 ; p<0.001\right)$ concentration. Both, microalgae concentration and specie had an effect on $\mathrm{Ch}$ $(p<0.001)$, as well as the interaction of both factors $(p<0.001)$. Higher microalgae concentration reduced $C h$ values, which suggest a loss of colour intensity after incorporation of microalgae into the soup. The observed loss in colour intensity was higher after incorporation of Spirulina sp. or Chlorella sp. when compared to Tetraselmis sp. Indeed, no differences were observed in the Ch values of samples CK and T1. 

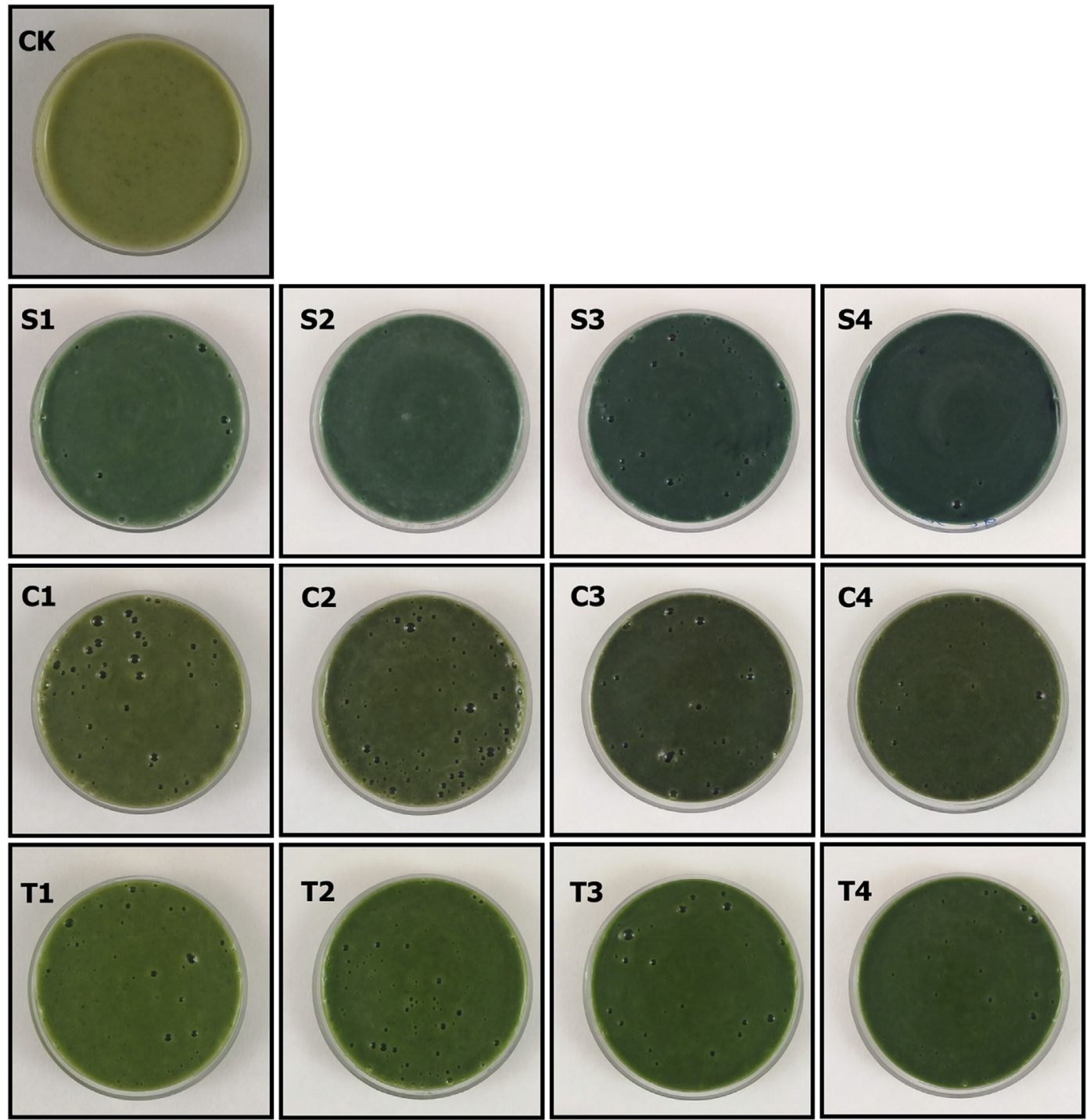

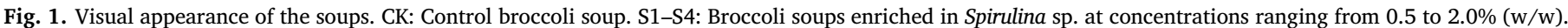

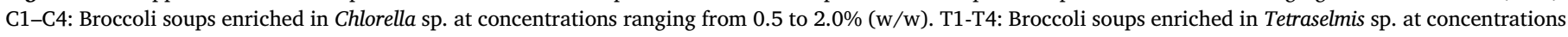
ranging from 0.5 to $2.0 \%(\mathrm{w} / \mathrm{w})$.

Moreover, in the current study, $\delta E$ was higher than three for all the formulated soups (data not shown), with those made using Spirulina sp. having significantly higher $\delta E$ values $(p<0.05)$. This suggests that the colour differences between the control and the microalgae-containing soups were visible to the human eye, especially for soups prepared using Spirulina sp. (Fig. 1). Furthermore, microalgae incorporation into the broccoli soup led to increased viscosity. A positive correlation was observed between microalgae concentration and viscosity $\left(r^{2}=0.8760\right.$; $p<0.05$ ).

\subsection{Total phenolic content and antioxidant activity}

The effect of microalgae inclusion on the TPC and antioxidant activity of the soups is shown in Fig. 2. Although cruciferous vegetables are specially known for their content in glucosinolates, these vegetables are also rich sources of polyphenols (Lafarga, Bobo, Viñas, Collazo, \& Aguiló-Aguayo, 2018; Lafarga, Viñas, Bobo, Simó, \& Aguiló-Aguayo, 2018). The TPC of the control soup was calculated as $30.02 \pm \mathrm{mg} /$ $100 \mathrm{~mL}$. Incorporation of microalgae into the broccoli soup resulted in increased TPC $(p<0.05)$ - an increase was also observed after incorporation of Tetraselmis sp. at a concentration of $0.5 \%(\mathrm{w} / \mathrm{v})$ but it was not statistically significant. In the current study, higher microalgae concentrations resulted in increased TPC $(p<0.05)$. Several recent studies demonstrated that microalgae contain important amounts of polyphenols, which contribute significantly to their antioxidant capacity (Custódio et al., 2012; Goiris et al., 2012; Hajimahmoodi et al., 2010). No major differences were observed in the TPC of soups formulated using either Chlorella sp. or Tetraselmis sp. (Fig. 2). This does not mean that Spirulina sp. contain higher concentrations of polyphenols, as their content depends largely on several factors including the cultivation conditions: nutrient limitation resulted in decreased TPC previously (Goiris et al., 2015). Results obtained for antioxidant activity correlate well with those obtained for TPC. Both DPPH and FRAP values were affected by microalgae incorporation $(p<0.05)$. The observed increase in antioxidant activity after incorporation of microalgae into the soup recipe was more evident when assessed using the DPPH assay. $\mathrm{C} 1$ and $\mathrm{T} 1$ showed a lower antioxidant capacity when compared to the control soup and when assessed using the FRAP assay ( $p<0.05)$. Although these differences were relatively small, they can be attributed to a dilution of the broccoli polyphenols of the control soup after incorporation of the microalgae and the broccoli boiling water. Also, the antioxidant capacity of Chlorella sp. and Tetraselmis sp. was lower than 
(A)

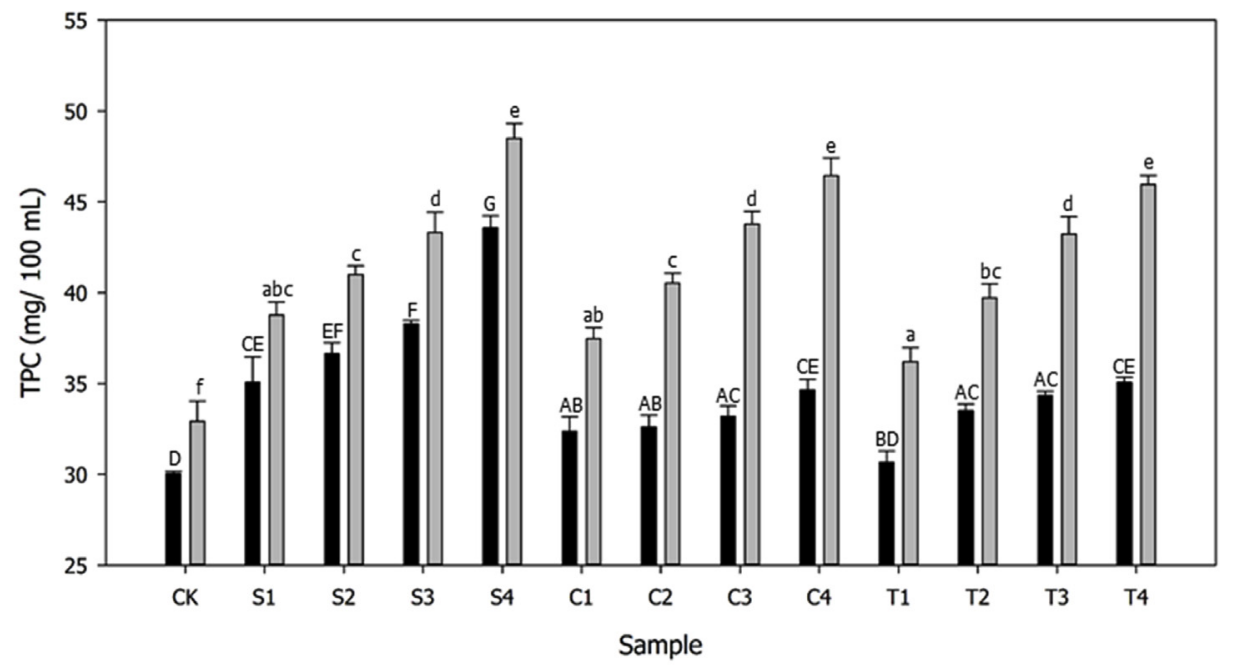

(B)

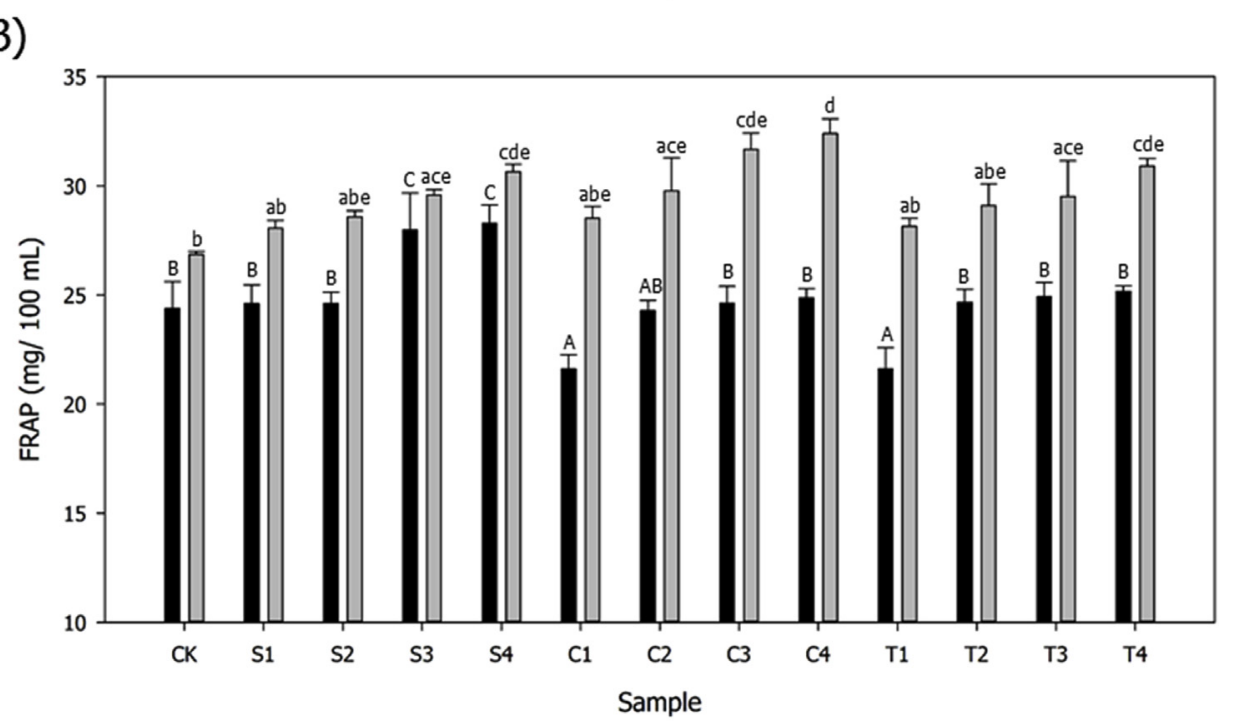

(C)

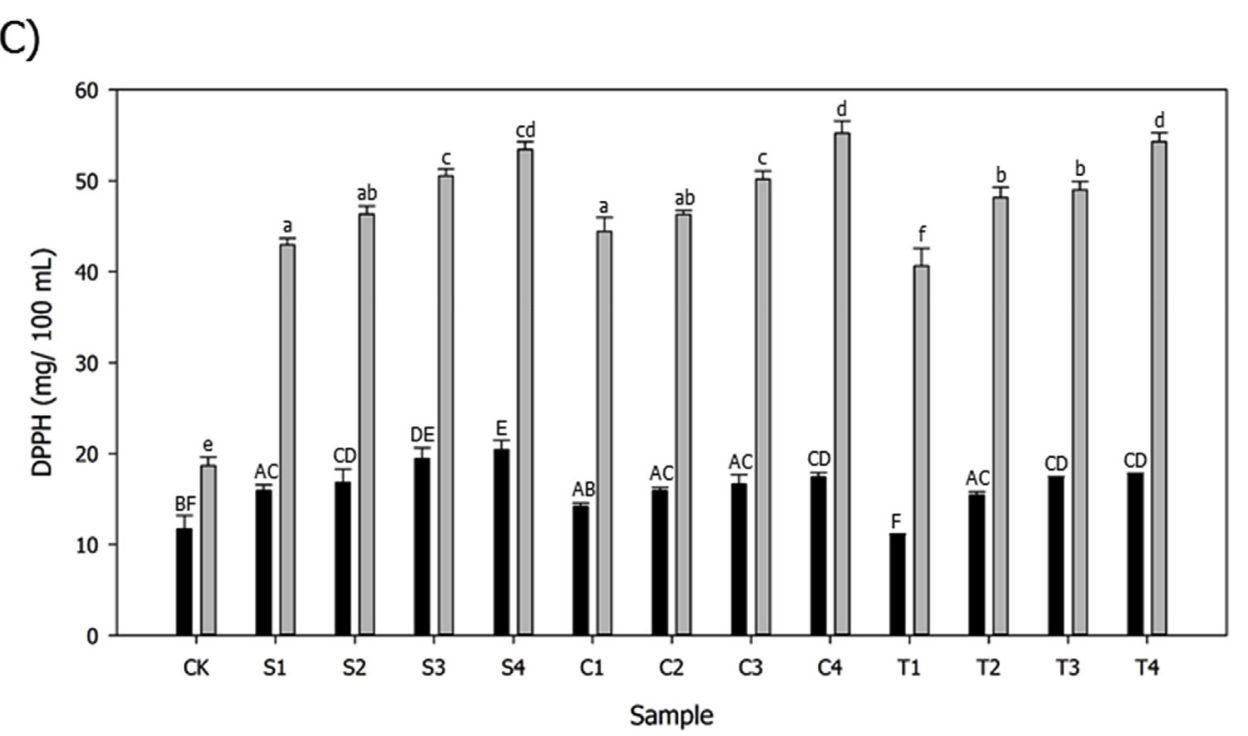

Fig. 2. (A) Total phenolic content and antioxidant activity assessed using the (B) FRAP and (C) DPPH assays of the control and microalgae-containing broccoli soups. Values represent mean values \pm S.D. of three independent determinations. Different capital letters indicate differences in either TPC or antioxidant activity of extracts obtained after a methanol:water extraction. Different lower case letters indicate significant differences between TPC or antioxidant activities of enzymatic digestive extracts obtained after a simulated gastrointestinal digestion. The criterion for statistical significance was $p<0.05$. (Legend: $\square$ after methanol:water extraction and $\square$ after in vitro gastrointestinal digestion). that of Spirulina sp. when assessed using both the FRAP and DPPH assays $(p<0.05)$.

The known "French paradox" ignited the interest of food processors and scientists on plant polyphenols. However, in order to exert a health effect in vivo, food polyphenols must first be bioavailable. Bioaccessibility is one of the main factors limiting bioavailability and has been defined as the release of compounds from their natural food matrix to be available for intestinal absorption (Stahl et al., 2002). 
Fig. 2 shows the amount of bioaccessible polyphenols after a simulated gastrointestinal digestion and the antioxidant capacity of the enzymatic digestive extracts. Overall, the TPC after the intestinal phase of digestion was higher for all the studied samples when compared to the initial stage - after a methanol:water extraction $(p<0.05)$. Similar results were previously reported for cereals (Pérez-Jiménez \& Saura-Calixto, 2005), pulses (Lafarga, Villaró, Bobo, Simó, \& Aguiló-Aguayo, 2019), and fruit (Chen et al., 2014). Higher microalgae concentrations resulted in higher amounts of bioaccessible polyphenols $(p<0.05)$. It is thought that free and some conjugated phenolic compounds are available for absorption in the human small and large intestines. However, those bound covalently to large polysaccharides may be absorbed after being released from cells by digestive enzymes or microorganisms in the intestinal lumen (Wang, He, \& Chen, 2014). It is possible that the strong $\mathrm{pH}$ variations suffered during the in vitro digestion, together with the activity of $\alpha$-amylase, pepsin, and pancreatin (the pancreatin utilized contained enzymatic components including trypsin, lipase, ribonuclease, and proteases which allowed hydrolysing proteins, carbohydrates, and fats) facilitated the release of polyphenols from the interior of the plant or microalgae cells. The longer extraction time could also partially explain these findings. One of the main problems associated with the utilisation of microalgae as raw material for the isolation of healthy compounds is the limited (mild) technological options and the high costs associated with the cell wall disruption and extraction steps. Results obtained herein could also promote the consumption of the whole microalgal biomass as they suggest that healthy compounds such as polyphenols can be bioavailable without a cell wall disruption step as they can be released during cooking and digestion. However, further studies are needed in order to prove this hypothesis. As mentioned previously, the methanol:water extracts of the soups formulated using Spirulina sp. showed a higher TPC $(p<0.05)$. That difference in TPC for soups containing Spirulina sp. was not observed in the enzymatic digestive extracts obtained after a simulated digestion. Indeed, the content of bioaccessible polyphenols was not affected by microalgae specie. Results obtained for antioxidant capacity after a simulated gastrointestinal digestion compare well with those observed for TPC. As expected, the antioxidant capacity of the enzymatic digestive extracts after the intestinal phase of digestion was higher for all the studied samples when compared to the initial stage $(p<0.05)$. This is probably caused by a higher content of polyphenols when compared to the extracts obtained after an extraction using methanol:water. Another reason could be that microalgae are protein-rich foods, and these proteins could have been hydrolysed during the simulated gastrointestinal digestion leading to the release of bioactive peptides with antioxidant activity (Ejike et al., 2017). Results reported in the current paper are consistent with previous studies that suggested that extractions using methanol or other organic solvents could be underestimating the actual antioxidant capacity of foods (Lafarga et al., 2019; Pérez-Jiménez \& Saura-Calixto, 2005).

\subsection{Visual and sensorial analysis}

The analysis of variance revealed that the visual acceptance of the soups was significantly affected by microalgae concentration $(p<0.001)$, specie $(p<0.001)$, and the interaction of both factors $(p<0.001)$. Visual and sensorial acceptance scores are listed in Table 3. Higher microalgae concentration resulted in reduced overall visual acceptance of the soups. However, no differences were observed between the overall visual acceptance scores of the control soup (CK) and formulations T1, T2, T3, C1, and C2. Visual scores also depended on the specie incorporated into the broccoli soup formulation $(p<0.001)$. As mentioned previously, colour attributes were significantly affected after incorporation of microalgae into the soup formulations (Table 2; $p<0.05$ ). It is widely accepted that colour of foods has a striking effect on consumers' expectations (Spence, 2018). A positive correlation was observed between the $L^{*}$ value of the soups and visual acceptance $\left(r^{2}=0.6304 ; p<0.05\right)$ suggesting that the panellists preferred soups with lighter colours. In addition, visual acceptance was negatively correlated with $a^{*}$ values $\left(r^{2}=0.7338 ; p<0.05\right)$ which means that the greener the colour of the soup, the higher the visual acceptance score. Soups formulated using Spirulina sp, obtained the lowest visual acceptability scores, which ranged from $4.6 \pm 0.3$ to $6.0 \pm 0.3$ for S4 and S1, respectively. In turn, incorporation of Tetraselmis sp, at concentrations ranging from 0.5 to $1.5 \%(\mathrm{w} / \mathrm{v})$ into the broccoli soups did not significantly affect its visual appearance: no differences were observed between the visual appearance scores of $\mathrm{T} 1$, $\mathrm{T} 2$, or T3 and the control (CK). This could be caused by the greener and lighter hue of the soups formulated using Tetraselmis sp. when compared to Spirulina sp. (Fig. 1).

Colour of foods can affect consumers' flavour perception (Spence, 2018). Previous studies even demonstrated that colour of soups can modulate satiety and thermal sensation (Suzuki et al., 2017). Therefore, in the current study, the flavour of foods was assessed under green lighting. Flavour scores are listed in Table 3. Flavour scores were significantly affected by microalgae concentration $(p<0.001)$, specie $(p<0.001)$, and the interaction of both factors $(p<0.001)$. No differences were observed between the flavour of the control soup and formulations S1, T1, and T2, which suggest that incorporation of Spirulina sp. and Tetraselmis sp. at low concentrations do not negatively affect flavour. However, higher microalgae concentrations resulted in decreased flavour scores. Incorporation of Chlorella sp. into broccoli soup, even at the lowest concentration studied in the current study, which was $0.5 \%(\mathrm{w} / \mathrm{v})$, resulted in a negative effect on flavour $(p<0.05)$. Chacón-Lee and González-Mariño (2010) reviewed the opportunities and challenges of microalgae utilisation in the food industry and suggested that incorporation of exotic-flavoured ingredients, such as Asian or Indian spices, together with the microalgae biomass would facilitate their incorporation into foods, especially for Western consumers. Other studies utilised sugar and butter to mask the flavour of microalgae in biscuits and obtained high flavour scores (Singh, Singh, Jha, Rasane, \& Gautam, 2015). This is important as unlike Japanese consumers, who consider functional foods a distinct food where the importance of their health benefits exceeds the importance of their sensory attributes, Western consumers do not seem to be willing to compromise taste for health (Grasso, Brunton, Lyng, Lalor, \& Monahan, 2014).

Results listed in Table 3 suggest that incorporation of microalgae did not significantly affect the texture of the soups, expect for a significantly lower texture score for S4 $(p<0.05)$. Finally, the acceptability index of the soups ranged between 56.7-80.0, 47.8-73.3, and 58.9-82.2\% for soups containing Spirulina sp., Chlorella sp., and Tetraselimis sp., respectively. For all the studied soups, the acceptability index was lower than that of the broccoli-only soup, which was calculated as $91.1 \%(p<0.05)$. The acceptability of the soups containing microalgae at lower concentrations was comparable to that of other products formulated using microalgae previously. Indeed, Lucas et al. (2018), recently reported an acceptability index of $82.2 \%$ for extruded snacks enriched in Spirulina. For a product to be accepted in terms of sensorial characteristics, it is necessary to achieve an acceptability index greater than $70 \%$ (Lucas et al., 2018). We can therefore expect that the manufactured microalgae-containing soups would have a good acceptance if commercialised. Indeed, when calculated as a percentage, the purchase intention of $\mathrm{S} 1, \mathrm{C} 1$, and $\mathrm{T} 1$ was $72.0,68.0$, and $82.0 \%$, respectively. The purchase intention was significantly lower for soups containing microalgae at higher concentrations as S4, C4, and T4 had a purchase intention ranging between 1 (certainly would not buy) and 2 (probably would not buy).

\section{Conclusions}

Results suggest that when incorporated at concentrations ranging from 0.5 to $1.0 \%(\mathrm{w} / \mathrm{v})$, microalgae can be used as an innovative 
Table 2

Physicochemical properties of the manufactured microalgae-containing soups.

\begin{tabular}{|c|c|c|c|c|c|c|}
\hline Sample & $L^{*}$ & $a^{*}$ & $b^{*}$ & $C h$ & $\mathrm{pH}$ & Viscosity (Pa.s) \\
\hline CK & $61,6 \pm 0,6^{A}$ & $-12,7 \pm 0,2^{\mathrm{I}}$ & $25,5 \pm 0,4^{\mathrm{A}}$ & $28,5 \pm 0,4^{\mathrm{A}}$ & $6.73 \pm 0.04^{\mathrm{E}}$ & $2,93 \pm 0,06^{\mathrm{F}}$ \\
\hline S1 & $44,4 \pm 0,5^{\mathrm{C}}$ & $-10,7 \pm 0,1^{\mathrm{F}}$ & $7,6 \pm 0,1^{\mathrm{G}}$ & $13,1 \pm 0,0^{\mathrm{G}}$ & $6.52 \pm 0.01^{\mathrm{G}}$ & $3,07 \pm 0,04^{\mathrm{E}}$ \\
\hline S2 & $39,0 \pm 0,1^{\mathrm{F}}$ & $-8,0 \pm 0,1^{\mathrm{D}}$ & $3,4 \pm 0,1^{\mathrm{H}}$ & $8,7 \pm 0,1^{\mathrm{H}}$ & $6.46 \pm 0.01^{\mathrm{H}}$ & $3,15 \pm 0,06^{\mathrm{DE}}$ \\
\hline S3 & $36,5 \pm 0,1^{\mathrm{G}}$ & $-6,4 \pm 0,1^{\mathrm{B}}$ & $1,5 \pm 0,2^{\mathrm{I}}$ & $6,6 \pm 0,1^{I}$ & $6.63 \pm 0.01^{\mathrm{F}}$ & $3,24 \pm 0,08^{\mathrm{C}}$ \\
\hline S4 & $33,9 \pm 0,2^{\mathrm{H}}$ & $-4,5 \pm 0,2^{\mathrm{A}}$ & $0,5 \pm 0,2^{\mathrm{J}}$ & $4,6 \pm 0,3^{\mathrm{J}}$ & $6.37 \pm 0.03^{I}$ & $3,33 \pm 0,16{ }^{\mathrm{AB}}$ \\
\hline $\mathrm{C} 1$ & $47,7 \pm 0,2^{\mathrm{B}}$ & $-10,9 \pm 0,1^{\mathrm{F}}$ & $18,4 \pm 0,3^{\mathrm{D}}$ & $21,4 \pm 0,3^{\mathrm{D}}$ & $6.73 \pm 0.03^{\mathrm{E}}$ & $3,02 \pm 0,05^{\mathrm{EF}}$ \\
\hline $\mathrm{C} 2$ & $42,9 \pm 0,1^{D}$ & $-9,7 \pm 0,2^{\mathrm{E}}$ & $15,4 \pm 0,4^{\mathrm{E}}$ & $18,2 \pm 0,5^{\mathrm{E}}$ & $6.63 \pm 0.04^{\mathrm{F}}$ & $3,24 \pm 0,06^{\mathrm{C}}$ \\
\hline $\mathrm{C} 3$ & $37,6 \pm 0,3^{G}$ & $-7,7 \pm 0,1^{\mathrm{C}}$ & $12,0 \pm 0,2^{\mathrm{F}}$ & $14,3 \pm 0,2^{\mathrm{F}}$ & $6.63 \pm 0.01^{\mathrm{F}}$ & $3,38 \pm 0,03^{\mathrm{B}}$ \\
\hline $\mathrm{C} 4$ & $39,2 \pm 0,2^{\mathrm{F}}$ & $-8,1 \pm 0,2^{\mathrm{D}}$ & $12,6 \pm 0,4^{\mathrm{F}}$ & $15,0 \pm 0,4^{\mathrm{F}}$ & $6.56 \pm 0.05^{\mathrm{FG}}$ & $3,56 \pm 0,06^{\mathrm{A}}$ \\
\hline $\mathrm{T} 1$ & $48,9 \pm 0,9^{\mathrm{B}}$ & $-15,8 \pm 0,3^{\mathrm{H}}$ & $23,0 \pm 0,4^{\mathrm{B}}$ & $27,8 \pm 0,6^{\mathrm{A}}$ & $6.83 \pm 0.04^{\mathrm{D}}$ & $3,03 \pm 0,03^{\mathrm{EF}}$ \\
\hline $\mathrm{T} 2$ & $43,7 \pm 0,6^{\mathrm{CD}}$ & $-15,3 \pm 0,1^{\mathrm{H}}$ & $20,4 \pm 0,2^{\mathrm{C}}$ & $25,5 \pm 0,2^{\mathrm{B}}$ & $7.07 \pm 0.02^{C}$ & $3,15 \pm 0,01^{D}$ \\
\hline $\mathrm{T} 3$ & $40,6 \pm 0,1^{\mathrm{E}}$ & $-14,4 \pm 0,3^{\mathrm{G}}$ & $18,1 \pm 0,1^{\mathrm{D}}$ & $23,2 \pm 0,2^{\mathrm{C}}$ & $7.13 \pm 0.02^{\mathrm{B}}$ & $3,25 \pm 0,07^{\mathrm{C}}$ \\
\hline $\mathrm{T} 4$ & $37,0 \pm 1,1^{\mathrm{G}}$ & $-12,7 \pm 0,0^{\mathrm{I}}$ & $15,7 \pm 0,1^{\mathrm{E}}$ & $20,1 \pm 0,1^{\mathrm{D}}$ & $7.20 \pm 0.03^{\mathrm{A}}$ & $3,29 \pm 0,01{ }^{\mathrm{BC}}$ \\
\hline
\end{tabular}

Composition of the soups is listed in Table 1. Values represent the mean of three independent measurements \pm S.D. Different letters in the same column indicate significant differences. The criterion for statistical significance was $p<0.05$.

Table 3

Visual and sensorial analysis of the microalgae-enriched broccoli soups.

\begin{tabular}{|c|c|c|c|c|c|c|}
\hline Sample & Visual appearance score & Flavour score* & Texture score & Overall acceptance score & Acceptability index (\%) & Purchase intention** \\
\hline CK & $7.8 \pm 0.2^{\mathrm{A}}$ & $8.2 \pm 0.1^{\mathrm{D}}$ & $7.9 \pm 0.2^{\mathrm{ABD}}$ & $8.2 \pm 0.1^{\mathrm{B}}$ & 91.1 & $4.6 \pm 0.1^{\mathrm{E}}$ \\
\hline S1 & $6.0 \pm 0.3^{\mathrm{BCDE}}$ & $7.5 \pm 0.3^{\mathrm{BD}}$ & $8.2 \pm 0.1^{\mathrm{A}}$ & $7.2 \pm 0.2^{\mathrm{ABF}}$ & 80.0 & $3.6 \pm 0.1^{\mathrm{AB}}$ \\
\hline S2 & $5.6 \pm 0.3^{\mathrm{CDE}}$ & $6.6 \pm 0.2^{\mathrm{ABE}}$ & $8.1 \pm 0.2^{\mathrm{AD}}$ & $6.7 \pm 0.2^{\mathrm{ABEF}}$ & 74.4 & $3.2 \pm 0.2^{\mathrm{ABF}}$ \\
\hline s3 & $5.0 \pm 0.3^{\mathrm{DE}}$ & $5.9 \pm 0.3^{\mathrm{ACEF}}$ & $7.8 \pm 0.2^{\mathrm{ABD}}$ & $5.7 \pm 0.3^{\mathrm{ACDE}}$ & 63.3 & $2.9 \pm 0.2^{\mathrm{ACF}}$ \\
\hline S4 & $4.6 \pm 0.3^{\mathrm{E}}$ & $5.4 \pm 0.2^{\mathrm{ACF}}$ & $6.6 \pm 0.2^{\mathrm{C}}$ & $5.1 \pm 0.3^{\mathrm{CDE}}$ & 56.7 & $1.7 \pm 0.1^{\mathrm{D}}$ \\
\hline $\mathrm{C} 1$ & $7.2 \pm 0.3^{\mathrm{AB}}$ & $6.6 \pm 0.3^{\mathrm{ABE}}$ & $8.2 \pm 0.1^{\mathrm{A}}$ & $6.6 \pm 0.3^{\mathrm{ABEF}}$ & 73.3 & $3.4 \pm 0.2^{\mathrm{ABF}}$ \\
\hline $\mathrm{C} 2$ & $6.6 \pm 0.3^{\mathrm{ABC}}$ & $5.8 \pm 0.2^{\mathrm{ACEF}}$ & $7.9 \pm 0.1 \mathrm{ABD}$ & $6.1 \pm 0.2^{\mathrm{ACEF}}$ & 67.8 & $2.8 \pm 0.2^{\mathrm{ACF}}$ \\
\hline C3 & $6.3 \pm 0.2^{\mathrm{BCD}}$ & $5.0 \pm 0.4^{\mathrm{CF}}$ & $7.3 \pm 0.3^{\mathrm{ABCD}}$ & $4.9 \pm 0.5^{\mathrm{CD}}$ & 54.4 & $2.1 \pm 0.2^{\mathrm{CD}}$ \\
\hline $\mathrm{C} 4$ & $6.0 \pm 0.3^{\mathrm{BCDE}}$ & $4.6 \pm 0.3^{C}$ & $6.9 \pm 0.2^{\mathrm{BC}}$ & $4.3 \pm 0.4^{\mathrm{D}}$ & 47.8 & $1.5 \pm 0.1^{\mathrm{D}}$ \\
\hline $\mathrm{T} 1$ & $7.8 \pm 0.2^{\mathrm{A}}$ & $7.3 \pm 0.2^{\mathrm{BD}}$ & $8.1 \pm 0.1 \mathrm{AD}$ & $7.4 \pm 0.2^{\mathrm{BF}}$ & 82.2 & $4.1 \pm 0.1^{\mathrm{BE}}$ \\
\hline $\mathrm{T} 2$ & $7.2 \pm 0.2^{\mathrm{AB}}$ & $6.9 \pm 0.2^{\mathrm{BDE}}$ & $8.0 \pm 0.1 \mathrm{ABD}$ & $7.0 \pm 0.2^{\mathrm{ABF}}$ & 77.8 & $3.5 \pm 0.2^{\mathrm{AB}}$ \\
\hline T3 & $7.1 \pm 0.2^{\mathrm{AB}}$ & $6.2 \pm 0.2^{\mathrm{ABEF}}$ & $7.1 \pm 0.2^{\mathrm{BCD}}$ & $6.1 \pm 0.2^{\mathrm{ACEF}}$ & 67.8 & $2.4 \pm 0.2^{\mathrm{CDF}}$ \\
\hline $\mathrm{T} 4$ & $6.1 \pm 0.2^{\mathrm{BCD}}$ & $6.1 \pm 0.2^{\mathrm{ABEF}}$ & $6.9 \pm 0.2^{\mathrm{BC}}$ & $5.3 \pm 0.4^{\mathrm{CDE}}$ & 58.9 & $2.0 \pm 0.2^{\mathrm{CD}}$ \\
\hline
\end{tabular}

Composition of the soups is listed in Table 1. * Flavour was assessed under green lighting conditions to mask the colour of the soups. ** Purchase intention was assessed using a 5-point hedonic scale. Values represent mean \pm SEM $(n=30)$. Different letters in the same column indicate significant differences between samples. The criterion for statistical significance was $p<0.05$.

ingredient in the manufacture of microalgae-enriched broccoli soup. However, when microalgae biomass was incorporated into the broccoli soup at higher concentrations, flavour and overall acceptability scores were low, especially for soups formulated using Chlorella sp. Sensorial analysis also suggested that consumers preferred soups with a lighter and greener hue. Results suggested that when formulated correctly, microalgae-containing foods show good consumer acceptance and this would allow increasing the utilisation of this valuable and underused ingredient. Moreover, microalgae-containing soups had higher phenolic content and antioxidant activity when compared to the control broccoli soups. The amount of bioaccessible polyphenols as well as the antioxidant capacity of the digestive enzymatic extracts was also higher in the microalgae-containing soups when compared to the controls suggesting healthier products. Results reported herein would open novel commercial opportunities for the utilization of microalgae as an ingredient in vegetables soups allowing not only to differentiate by using a "trendy" ingredient but also to promote health. Further studies will assess which compounds were responsible for the observed increase in antioxidant activity as well as the effect of thermal processing and/or high pressure processing on the health-promoting compounds found in the soup.

\section{Acknowledgements}

This work was supported by the CERCA Programme of Generalitat de Catalunya. T. Lafarga and I. Aguiló-Aguayo are in receipt of Juan de la Cierva (FJCI-2016-29541) and Ramon y Cajal (RYC-2016-19949) contracts respectively, both funded by the Spanish Ministry of Economy,
Industry, and Competitiveness. Microalgae biomass was kindly provided by Fundación Cajamar (Almería, Spain).

\section{References}

Acién Fernández, F. G., Fernández Sevilla, J. M., \& Molina Grima, E. (2018). Contribución de las microalgas al desarrollo de la bioeconomía. In A. Aguilar, D. Ramón, \& F. J. Egea (Eds.). Bioeconomía y desarrollo sostenible (pp. 309-332). Almería, Spain: Cajamar Caja Rural.

AESAN (2014). Report of the Scientific Committee of the Spanish Agency for Food Safety and Nutrition on a request for initial assessment for marketing of the marine microalgae Tetraselmis chuii under Regulation (EC) No 258/97 on novel foods and novel food ingredients. Revista del Comite Cientifico de la AESAN, 18, 11-28.

Amaral, G. V., Silva, E. K., Costa, A. L. R., Alvarenga, V. O., Cavalcanti, R. N., Esmerino, E. A., et al. (2018). Whey-grape juice drink processed by supercritical carbon dioxide technology: Physical properties and sensory acceptance. Lebensmittel-Wissenschaft \& Technologie, 92, 80-86.

Becker, E. W. (2007). Micro-algae as a source of protein. Biotechnology Advances, 25, 207-210.

Caporgno, M. P., \& Mathys, A. (2018). Trends in microalgae incorporation into innovative food products with potential health benefits. Frontiers in Nutrition, 5, 58.

Chacón-Lee, T. L., \& González-Mariño, G. E. (2010). Microalgae for "healthy" food$\mathrm{s}$ - possibilities and challenges. Comprehensive Reviews in Food Science and Food Safety, 9, 655-675.

Chen, G.-L., Chen, S.-G., Zhao, Y.-Y., Luo, C.-X., Li, J., \& Gao, Y.-Q. (2014). Total phenolic contents of 33 fruits and their antioxidant capacities before and after in vitro digestion. Industrial Crops and Products, 57, 150-157.

Custódio, L., Justo, T., Silvestre, L., Barradas, A., Duarte, C. V., Pereira, H., ... Varela, J. (2012). Microalgae of different phyla display antioxidant, metal chelating and acetylcholinesterase inhibitory activities. Food Chemistry, 131, 134-140.

Ejike, C. E. C. C., Collins, S. A., Balasuriya, N., Swanson, A. K., Mason, B., \& Udenigwe, C. C. (2017). Prospects of microalgae proteins in producing peptide-based functional foods for promoting cardiovascular health. Trends in Food Science \& Technology, 59, 30-36.

Garrido-Cardenas, J. A., Manzano-Agugliaro, F., Acien-Fernandez, F. G., \& Molina-Grima, 
E. (2018). Microalgae research worldwide. Algal Research, 35, 50-60.

Goiris, K., Muylaert, K., Fraeye, I., Foubert, I., De Brabanter, J., \& De Cooman, L. (2012). Antioxidant potential of microalgae in relation to their phenolic and carotenoid content. Journal of Applied Phycology, 24, 1477-1486.

Goiris, K., Van Colen, W., Wilches, I., León-Tamariz, F., De Cooman, L., \& Muylaert, K. (2015). Impact of nutrient stress on antioxidant production in three species of microalgae. Algal Research, 7, 51-57.

Gouveia, L., Coutinho, C., Mendonça, E., Batista, A. P., Sousa, I., Bandarra, N. M., et al. (2008). Functional biscuits with PUFA- $\omega 3$ from Isochrysis galbana. Journal of the Science of Food and Agriculture, 88, 891-896.

Grasso, S., Brunton, N., Lyng, J., Lalor, F., \& Monahan, F. (2014). Healthy processed meat products-Regulatory, reformulation and consumer challenges. Trends in Food Science \& Technology, 39, 4-17.

Hajimahmoodi, M., Faramarzi, M. A., Mohammadi, N., Soltani, N., Oveisi, M. R., \& Nafissi-Varcheh, N. (2010). Evaluation of antioxidant properties and total phenolic contents of some strains of microalgae. Journal of Applied Phycology, 22, 43-50.

Kumar, K. S., Ganesan, K., Selvaraj, K., \& Rao, P. S. (2014). Studies on the functional properties of protein concentrate of Kappaphycus alvarezii (Doty) Doty-An edible seaweed. Food Chemistry, 153, 353-360.

Lafarga, T., Álvarez, C., Bobo, G., \& Aguiló-Aguayo, I. (2018). Characterization of functional properties of proteins from Ganxet beans (Phaseolus vulgaris L. var. Ganxet) isolated using an ultrasound-assisted methodology. Lebensmittel-Wissenschaft \& Technologie, 98, 106-112.

Lafarga, T., Bobo, G., Viñas, I., Collazo, C., \& Aguiló-Aguayo, I. (2018). Effects of thermal and non-thermal processing of cruciferous vegetables on glucosinolates and its derived forms. Journal of Food Science \& Technology, 55, 1973-1981.

Lafarga, T., Ruiz-Aguirre, I., Abadias, M., Viñas, I., Bobo, G., \& Aguiló-Aguayo, I. (2019). Effect of thermosonication on the bioaccessibility of antioxidant compounds and the microbiological, physicochemical, and nutritional quality of an anthocyanin-enriched tomato juice. Food and Bioprocess Technology, 12(1), 147-157.

Lafarga, T., Villaró, S., Bobo, G., Simó, J., \& Aguiló-Aguayo, I. (2019). Bioaccessibility and antioxidant activity of phenolic compounds in cooked pulses. International Journal of Food Science and Technology, 54, 1816-1823.

Lafarga, T., Viñas, I., Bobo, G., Simó, J., \& Aguiló-Aguayo, I. (2018). Effect of steaming and sous vide processing on the total phenolic content, vitamin $\mathrm{C}$ and antioxidant potential of the genus Brassica. Innovative Food Science \& Emerging Technologies, 47, $412-420$.

Li, H.-B., Cheng, K.-W., Wong, C.-C., Fan, K.-W., Chen, F., \& Jiang, Y. (2007). Evaluation of antioxidant capacity and total phenolic content of different fractions of selected microalgae. Food Chemistry, 102, 771-776.
Lucas, B. F., Morais, M. G. d., Santos, T. D., \& Costa, J. A. V. (2018). Spirulina for snack enrichment: Nutritional, physical and sensory evaluations. Lebensmittel-Wissenschaft \& Technologie, 90, 270-276.

Minekus, M., Alminger, M., Alvito, P., Ballance, S., Bohn, T., Bourlieu, C., ... Dupont, D. (2014). A standardised static in vitro digestion method suitable for food-an international consensus. Food \& Function, 5, 1113-1124.

Pérez-Jiménez, J., \& Saura-Calixto, F. (2005). Literature data may underestimate the actual antioxidant capacity of cereals. Journal of Agricultural and Food Chemistry, 53 5036-5040.

Rizwan, M., Mujtaba, G., Memon, S. A., Lee, K., \& Rashid, N. (2018). Exploring the potential of microalgae for new biotechnology applications and beyond: A review. Renewable and Sustainable Energy Reviews, 92, 394-404.

Rodríguez De Marco, E., Steffolani, M. E., Martínez, C. S., \& León, A. E. (2014). Effects of spirulina biomass on the technological and nutritional quality of bread wheat pasta. Lebensmittel-Wissenschaft \& Technologie, 58, 102-108.

Sandmann, A., Brown, J., Mau, G., Saur, M., Amling, M., \& Barvencik, F. (2015). Acceptance of vitamin D-fortified products in Germany - a representative consumer survey. Food Quality and Preference, 43, 53-62.

Singh, P., Singh, R., Jha, A., Rasane, P., \& Gautam, A. K. (2015). Optimization of a process for high fibre and high protein biscuit. Journal of Food Science and Technology, 52, 1394-1403.

Souza, F. P., Balthazar, C. F., Guimarães, J. T., Pimentel, T. C., Esmerino, E. A., Freitas, M. Q., et al. (2019). The addition of xyloligoosaccharide in strawberry-flavored whey beverage. Lebensmittel-Wissenschaft \& Technologie, 109, 118-122.

Spence, C. (2018). Background colour \& its impact on food perception \& behaviour. Food Quality and Preference, 68, 156-166.

Stahl, W., van den Berg, H., Arthur, J., Bast, A., Dainty, J., Faulks, R. M., ... Holst, B. (2002). Bioavailability and metabolism. Molecular Aspects of Medicine, 23, 39.

Suzuki, M., Kimura, R., Kido, Y., Inoue, T., Moritani, T., \& Nagai, N. (2017). Color of hot soup modulates postprandial satiety, thermal sensation, and body temperature in young women. Appetite, 114, 209-216.

Vaz, B. d. S., Moreira, J. B., Morais, M. G. d., \& Costa, J. A. V. (2016). Microalgae as a new source of bioactive compounds in food supplements. Current Opinion in Food Science, 7, 73-77.

Waghmare, A. G., Salve, M. K., LeBlanc, J. G., \& Arya, S. S. (2016). Concentration and characterization of microalgae proteins from Chlorella pyrenoidosa. Bioresources and Bioprocessing, 3, 16.

Wang, T., He, F., \& Chen, G. (2014). Improving bioaccessibility and bioavailability of phenolic compounds in cereal grains through processing technologies: A concise review. Journal of Functional Foods, 7, 101-111. 